\title{
ANALYSIS OF THERMAL PROPERTIES AND HEAT LOSS IN CONSTRUCTION AND ISOTHERMAL MATERIALS OF MULTILAYER BUILDING WALLS
}

\author{
Arkadiusz Urzędowski ${ }^{1}$, Dorota Wójcicka-Migasiuk' ${ }^{1}$ Joanna Styczeń2
}

1 Lublin University of Technology, Fundamentals of Technology Faculty, ul. Nadbystrzycka 38, 20-618 Lublin, e-mail: a.urzedowski@pollub.pl, d.wojcicka-migasiuk@pollub.pl

2 Lublin University of Technology, Civil Engineering and Architecture Faculty, ul. Nadbystrzycka 38, 20-618 Lublin, e-mail: j.styczen@pollub.pl

Received: 2016.12.04

Accepted: 2017.03.09

Published: 2017.03.01

\begin{abstract}
The article discusses the impact of vertical partition, technology on thermal insulation of the building, and the resulting savings and thermal comfort of residents. The study is carried out as an analysis of three selected design solutions including such materials as: aerated concrete elements, polystyrene, ceramic elements, concrete, mineral plaster. Simulation results of heat transfer in a multi-layered wall, are subjected to a detailed analysis by means of thermal visual methods. The study of existing structures, helped to identify the local point of heat loss by means of infrared technology leading to determination of $\mathrm{U}$-value reduction by $36 \%$ in maximum for the described 3 types of structure.
\end{abstract}

Keywords: thermal insulation, heat transfer coefficient, thermography, building materials, low-energy houses.

\section{INTRODUCTION}

In connection with the constant need to reduce the heat transfer coefficient of building envelope resulting from changes in legal regulations, manufacturers of insulation materials compete with each other in more and more advanced solutions. They aim to introduce new products, or to modify the structure and thermal properties of the existing ones, in a way to minimize unwanted heat loss [1, 3, 4]. It is possible to achieve this task by careful modification of the type of insulation, the thickness of the structure, moisture content, type of heat exchange, etc.

A way bulkhead insulation, plays a very important role in the reduction of energy consumption. In this work, we attempt to answer the question - which of the selected solutions, can provide thermal parameters desirable for passive houses and low energy, without unduly increasing the thickness of the structure. For this purpose, the calculation was carried out within the heat transfer analysis and the advantage of heat flow. The analysis was carried out for three selected systems of structural exterior walls. The analysis is based on a comparison of the processes occurring in the vertical systems made by means of three technologies. The Complex mechanism of heat exchange though advanced layer structures has not been fully described yet. A comparative analysis, however, can help to understand and point out the most important factors determining the process of heat exchange in vertical wall structures in buildings.

Thermal dynamic of heat transfer may take place by convection, conduction and radiation. However, in practice it can be presented together, leading to the phenomenon of combined heat transfer or its acquisition. Heat acquisition occurs between a fluid and a solid, of different 
temperatures [10]. The complexity of this process consists of heat conduction through a fluid layer at the surface of the material and the convection occurring in the fluid. The heat transfer takes place between two fluids of different temperatures, separated by a wall and the process consists of a sequence of acquisition, conduction and re-acquisition. This phenomena occur in the complex structures of buildings.

The mechanism of heat conduction is described by Kirchoff - Fouerier law [8], which has the form:

$$
\frac{\partial T}{\partial t}+(\vec{w} \cdot \nabla) \cdot T=\frac{1}{\rho \cdot c_{p}} \cdot\left[\nabla(\lambda \cdot \nabla T)+q_{v}\right]
$$

In this form, the solution of equation can be determined only by approximate numerical methods [5]. However, assuming the value of individual equation component amounts to zero as follows:

- the temperature field does not depend on time $\partial \mathrm{T} / \partial \mathrm{t}=0$

- there is no internal heat source $\mathrm{q}_{\mathrm{v}}=0$

- there is no convection $(\vec{w} \cdot \nabla) \cdot T=0$

One can get the equation for steady during the state assuming the conduction without internal heat sources:

$$
\nabla(\lambda \cdot \nabla T)=0
$$

which can be stored in Cartesian coordinates as:

$$
\frac{d^{2} T}{d x^{2}}=0
$$

after the transformation one can get the formula for proper conduction resistance:

$$
R_{\lambda}=\frac{\delta}{\lambda},\left(\mathrm{m}^{2} \mathrm{~K} / \mathrm{W}\right)
$$

where: $\delta$ - thickness of the wall (m), $\lambda$ - thermal conductivity of the material $(\mathrm{W} / \mathrm{mK})$

The paper considers a steady conduction through a multilayer wall structure composed of a flat baffle of n-layers and of different thickness. The values of the heat transfer coefficients are independent on temperature (i.e.. $\lambda=$ const). In the simplified method, one can assume that the structure is made of homogeneous materials.

For the flat wall, the value of the heat flux $\mathrm{q}$ flowing through the structures can be expressed by means of the following formula:

$$
q,=\frac{T_{w 1}-T_{w, n+1}}{\sum_{i=1}^{n} R_{\lambda_{i}}}
$$

where:

$$
\sum_{i=1}^{n} R_{\lambda_{i}}=\left(\frac{\delta_{1}}{\lambda_{1}}+\frac{\delta_{2}}{\lambda_{2}}+\cdots+\frac{\delta_{i}}{\lambda_{i}}\right)
$$

$\delta_{1}, \delta_{2}, \ldots, \delta_{\mathrm{i}}-$ width of successive layer in the baffles $(\mathrm{m})$

$\lambda_{1}, \lambda_{2}, \ldots, \lambda_{i}-$ heat transfer coefficients of the successive layers $(\mathrm{W} / \mathrm{mK})$

$\mathrm{T}_{\mathrm{w} 1}, \mathrm{~T}_{\mathrm{w} 2}, \ldots, \mathrm{T}_{\mathrm{wi}}-$ the temperature of the heat transfer partition successive layers $(\mathrm{K})$

Hence the definition of heat transfer coefficient $\mathrm{U}$ :

$$
U=\frac{1}{R},\left(\mathrm{~W} / \mathrm{m}^{2} \mathrm{~K}\right)
$$

\section{METHODS}

In this work, the analysis included three construction systems of external walls - two performed in traditional technologies and the innovative one called the permanent formwork system. Among so many solutions available on the market, the author select the two most popular technologies of building walls: the ceramic and the elements of aerated concrete. The walls constructed with these materials are double-layer - the inner side of structural layer, and on the outside - thermal insulation made of expanded polystyrene.

Calculations and simulations have been performed also for innovative technology of permanent shuttering, which is gaining a wider and wider group of followers. This technology allows for a triple construction. They consist of concrete, surrounded with extruded polystyrene on both sides that has a good thermal insulation parameters. The calculation is based on the total thickness of the divisions of $36,5 \mathrm{~cm}$.

Calculations of heat transfer coefficient have been performed on the basis of formulas (5-7).

System No. I - system composed of the aerated element $[250 \times 249 \times 373 \mathrm{~mm}]$ insulated with panels of expanded polystyrene of $100 \mathrm{~mm}$ thickness, fixed by means of adhesive and pegs.

System No. II - system composed of ceramics $[240 \times 240 \times 590 \mathrm{~mm}]$, insulated with panels of expanded polystyrene of $110 \mathrm{~mm}$ thickness, fixed by means of adhesive and pegs.

System No. III - system composed of bulkhead fittings made of extruded polystyrene Izodom $[350 \times 250 \times 1000 \mathrm{~mm}]$, filled with a concrete core of $150 \mathrm{~mm}$ width.

Another factor having a significant effect on thermal properties of the building envelope are 

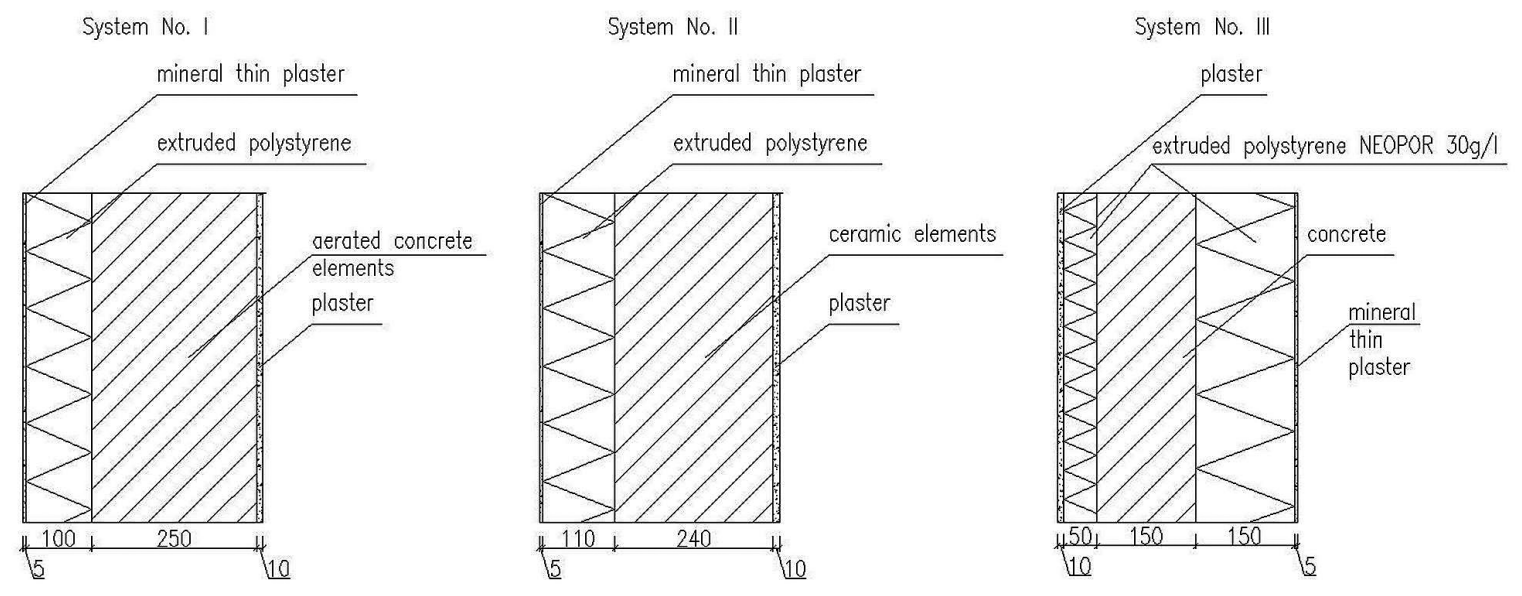

Fig. 1. General system of wall layers

Table 1. Characteristics parameters of 3 considered systems

\begin{tabular}{|c|c|c|c|c|}
\hline \multicolumn{5}{|c|}{ System No. I - WALL OF AERATED CONCRETE ELEMENTS } \\
\hline Characteristics & d & $\lambda$ & $\mathrm{R}$ & $U$ \\
\hline & {$[\mathrm{m}]$} & {$[\mathrm{W} / \mathrm{mK}]$} & {$\left[\mathrm{m}^{2} \mathrm{~K} / \mathrm{W}\right]$} & {$\left[\mathrm{W} / \mathrm{m}^{2} \mathrm{~K}\right]$} \\
\hline The surface resistance of the inner side & & & 0,130 & \\
\hline Plaster & 0,010 & 0,400 & 0,025 & \\
\hline Aerated concrete elements & 0,240 & 0,140 & 1,714 & \\
\hline Extruded polystyrene & 0,110 & 0,031 & 3,548 & \\
\hline Mineral thin plaster & 0,005 & 1,000 & 0,005 & \\
\hline The surface resistance of the outer side & & & 0,040 & \\
\hline Total thickness & 0,365 & & 5,463 & 0,183 \\
\hline \multicolumn{5}{|c|}{ System No. II - WALL OF CERAMIC COMPONENTS } \\
\hline \multirow[t]{2}{*}{ Characteristics } & $d$ & $\lambda$ & $\mathrm{R}$ & $U$ \\
\hline & {$[\mathrm{m}]$} & {$[\mathrm{W} / \mathrm{mK}]$} & {$\left[\mathrm{m}^{2} \mathrm{~K} / \mathrm{W}\right]$} & {$\left[\mathrm{W} / \mathrm{m}^{2} \mathrm{~K}\right]$} \\
\hline The surface resistance of the inner side & & & 0,130 & \\
\hline Plaster & 0,010 & 0,400 & 0,025 & \\
\hline Ceramic elements & 0,250 & 0,283 & 0,883 & \\
\hline Extruded polystyrene & 0,100 & 0,031 & 3,226 & \\
\hline Mineral thin plaster & 0,005 & 1,000 & 0,005 & \\
\hline The surface resistance of the outer side & & & 0,040 & \\
\hline Total thickness & 0,365 & & 4,309 & 0,232 \\
\hline \multicolumn{5}{|c|}{ System No. III - PERMANENT SHUTTERING SYSTEM IZODOM } \\
\hline \multirow[t]{2}{*}{ Characteristics } & d & $\lambda$ & $\mathrm{R}$ & $U$ \\
\hline & [m] & {$[\mathrm{W} / \mathrm{mK}]$} & {$\left[\mathrm{m}^{2} \mathrm{~K} / \mathrm{W}\right]$} & {$\left[\mathrm{W} / \mathrm{m}^{2} \mathrm{~K}\right]$} \\
\hline The surface resistance of the inner side & & & 0,130 & \\
\hline Plaster & 0,010 & 0,400 & 0,025 & \\
\hline Extruded polystyrene NEOPOR 30g/l & 0,050 & 0,031 & 1,613 & \\
\hline Concrete & 0,150 & 1,700 & 0,088 & \\
\hline Extruded polystyrene NEOPOR 30g/l & 0,150 & 0,031 & 4,839 & \\
\hline Mineral thin plaster & 0,005 & 1,000 & 0,005 & \\
\hline Total thickness & 0,365 & & 6,740 & 0,148 \\
\hline
\end{tabular}


thermal bridges. Thermal bridges can be broadly described as locally limited areas in the building envelope of high heat permeability, in comparison to adjacent surfaces. This increased heat permeability results in higher energy losses from the building, consequently, increases operating costs. A reduction of temperature on the inner surface of a wall causes a risk of a mold formation. In places where thermal bridges occur we also observe the formation of water vapor condensation and the related occurrence of a number of other destructive processes, damaging wall structures in total but, in particular the layer of coating and its finishing.

The formation of thermal bridges is unacceptable because their consequences are substantial. greater heat loss, increased risk of mold formation, the dangerous surface condensation, increased risk of negative effects on human health i.e.: allergies, breathing problems etc., and also local cooling sensation are the most significant consequences. Thermal bridges can be avoided taking into account a fundamental principle: continuity of the thermal insulation (laid on the outer side of the building envelope) must be maintained.

There are two types of thermal bridges distinguished due their location: material and geometric. Geometric thermal bridges are created when the surface of heat emission is much larger than the surface of receiving. This phenomenon can be seen at the corners of buildings.

The material thermal bridges are formed in places where different materials adhere to each other and their thermal conductivities differ significantly [2], as in an example when the anchor assembly is adjacent to polystyrene, used in conventional solutions. Then the heat flux finds its way to passe through the insulation layer, leading to a

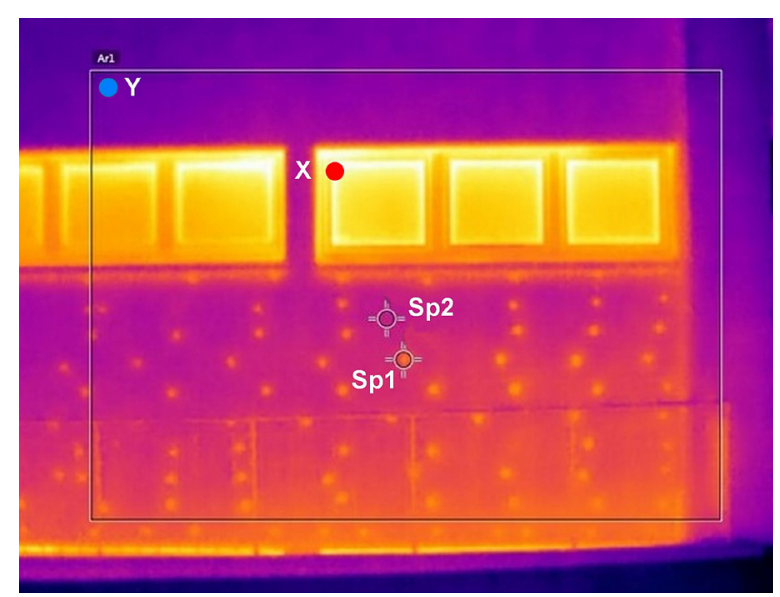

Fig. 2. Spot thermal bridges caused in fixing foamed polystyrene panels for facades much more intensive heat loss point. These losses, can be visualized using infrared technology. The image presented in Figure 1. shows a section of a façade. The visualization was made with an infrared camera FlirT640bx. The elevation, was subjected to thermal modernization. There are clearly marked yellow spots on the purple background they are the places where anchors fix polystyrene. Talking into account that it is recommended to use 4-5 anchors per $1 \mathrm{~m}^{2}$ wall, this phenomenon is very disadvantageous for the thermal insulation of buildings, increasing the heat loss of c.a. $1 \%$.

\section{DISCUSSION OF RESULTS}

On the basis of the presented results, it can be concluded that system III is characterized by the best thermal properties. The value of the coefficient of heat equals only $0.148\left[\mathrm{~W} / \mathrm{m}^{2} \mathrm{~K}\right]$, at the same time meeting strict criteria required for passive buildings. In the other two cases, the design values of thermal conductivity were $U=0.232$ $\left[\mathrm{W} / \mathrm{m}^{2} \mathrm{~K}\right]$ and $\mathrm{U}=0.183\left[\mathrm{~W} / \mathrm{m}^{2} \mathrm{~K}\right]$ respectively. Thanks to innovative technology based on materials of low thermal conductivity it was possible to reduce the obtained value by $36.21 \%$ for Izodom technology in relation to the ceramic blocks and by $19.13 \%$ in relation to the concrete blocks.

To get a similar U-value for walls made of ceramic blocks and aerated concrete, it would increase the thickness of the insulation of $76 \mathrm{~cm}$ and $40 \mathrm{~cm}$, respectively. Such a significant increase in wall thickness, would lead to a significant reduction of the room surface inside the house. This relationship can be illustrated by means of an example of two-storey detached house, built in a formwork technology. If the floor area is $144 \mathrm{~m}^{2}$ changing materials on the walls into ceramic blocks limits the floor area down to $143.04 \mathrm{~m}^{2}$. It decreases the floor area by about $1,92 \mathrm{~m}^{2}$. While at the aerated concrete block walls the obtained usable area is $142,19 \mathrm{~m}^{2}$ and $3,62 \mathrm{~m}^{2}$ is lost. Thus, even with small areas of buildings one can save up to several square meters which is of special importance for habitants at small buildings.

Figure 2 presents the results a of heat transfer study through a section of the insulated exterior wall of the building. The two indicated spots are marked as $\mathrm{Sp} 1$ and $\mathrm{Sp} 2$. Sp1 temperature is $6.6^{\circ} \mathrm{C}$ and at point $\mathrm{Sp} 2$ it is only $4.9^{\circ} \mathrm{C}$. The measurement result of the temperature at point $\mathrm{Sp} 2$ represents the range of the surface temperature marked in lower spectrum (pink colors range) of the available palette. While point $\mathrm{Sp} 1$ is a place in 


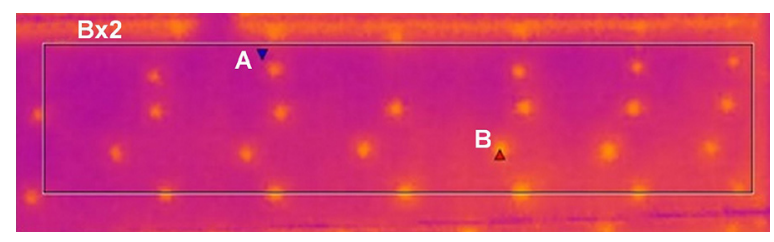

Fig. 3. Distribution of temperature on the wall in the area BX2

which the guide pin fix the thermal insulation and makes a thermal bridge. This situation is unacceptable in energy-efficient buildings and passive ones. In the picture (Fig. 2) the caused thermal bridges around the window frame are clearly visible. The temperature difference between point $\mathrm{X}$ (red) of $12.2^{\circ} \mathrm{C}$ and point $\mathrm{Y}$ (blue) of $3.8^{\circ} \mathrm{C}$ is $8.4^{\circ} \mathrm{C}$. It is distinctly visible that the poor design, selection and installation can lead to quite substantial heat losses.

Further consideration relates to the selected area of $0,43 \times 2,06 \mathrm{~m}$, highlighted in Figure 3 as $\mathrm{Bx} 2$. This is a two-layer wall and its construction is made in the System II. The minimum value of the temperature on the outer side of the layer wall, in this area (blue triangle, point $\mathrm{A}$ ) is $4.7^{\circ} \mathrm{C}$, the max value (red triangle, point $\mathrm{B}$ ) is $7.2^{\circ} \mathrm{C}$, while the average value is $\mathrm{T}_{\text {out }}=5.1^{\circ} \mathrm{C}$. The ambient outdoor temperature during the measurement was $\mathrm{T}_{\mathrm{a}}=0.5^{\circ} \mathrm{C}$, and the indoor ambient temperature $\mathrm{T}_{\mathrm{p}}=23^{\circ} \mathrm{C}$. The results obtained by examination of thermal imaging provide estimates of heat transfer coefficient [6], according to the formula:

$$
U=\frac{\alpha_{\text {out }}\left(T_{\text {out }}-T_{a}\right)}{T_{\text {out }}-T_{a}}
$$

where: $\alpha_{\text {out }}$ - transfer coefficient and the heat transfer partition at the interface with the outside of the building, $\mathrm{W} / \mathrm{m}^{2} \mathrm{~K}$.

This consideration assumes that the effects of solar radiation and the influence of such parameters as humidity and pressure, which may change the value of the coefficient of heat transfer, are neglected. U-value is obtained by Equation (8) at the value of $0.198\left[\mathrm{~W} / \mathrm{m}^{2} \mathrm{~K}\right]$. This assumption can be made when total temperature differences are $5 \mathrm{~K}$ and solar radiator occurs mainly as a dispersed component. The obtained result is similar but does not coincide with the value $\mathrm{U}$, determined for the second analytical method. The difference is 0.015 $\left[\mathrm{W} / \mathrm{m}^{2} \mathrm{~K}\right]$ and it follows directly from the conditions in which the thermal imaging measurement was carried out, taking into account the occurrence of thermal bridges in place of pegs.

\section{CONCLUSIONS}

The analysis of the thermal properties of three selected structural systems external wall, give results which indicate a significantly improved insulating properties of the wall built in the technology of permanent shuttering.

Thanks to the innovative technology based on materials of low thermal conductivity, c.a. $36.21 \%$ reduction in the U-values obtained for Izodom technology in relation to the ceramic blocks (System II) and $19.13 \%$ in relation to the concrete blocks (System III) was observed. One can find out that coefficient $\mathrm{U}=0.148\left[\mathrm{~W} / \mathrm{m}^{2} \mathrm{~K}\right]$, for Systems II and III, would require to increase the insulation thickness of $76 \mathrm{~cm}$ and $40 \mathrm{~cm}$, respectively in comparison to System I. The method uses thermal imaging and allows to obtain sufficiently precise results of the heat transfer coefficient, which also confirms the usefulness of the test equipment in the conducted analysis.

\section{REFERENCES}

1. Feist W., Basics of passive constructions, Polish Passive House Institute, Gdańsk, 2006 (in Polish).

2. Information folder Izodom 2000 Polska, No. 11, January 2014 (in Polish).

3. Królczyk B., Energy-efficient and passive construction: problem identification, Kunke Poligrafia, Poznań, 2013 (in Polish).

4. Lewandowski W., Environmentally friendly renewable energy sources, Publisher WNT, Warszawa 2012 (in Polish).

5. Ślusarek J., Wilk-Słomka B., Thermal processes in building envelopes of a complex structure, Publisher Silesian University of Technology, Gliwice, 2010 (in Polish).

6. Technical folder SPB Part 1 - Hygrothermal design of cellular concrete walls - full structures, February 2013 (in Polish).

7. Urzędowski A., Izodom - a breakthrough in wall isolation, Inżynier budownictwa, Oct. 2016, 83 (in Polish).

8. Urzędowski A., Wójcicka-Migasiuk D., Visual analysis of heat transport in unique object, Advances in Science and Technology Research Journal, 2015, 9(28), 153-159.

9. Wall solutions catalogue Porotherm, WBC, 2014 (in Polish).

10. Wójcicka-Migasiuk D., The analysis of heat exchange through solar walls, Lubelskie Towarzystwo Naukowe, Lublin 2008 (in Polish).

11. Wójcicka-Migasiuk D., Urzędowski A., Analysis of demand, loss and profits of energy in passive building with thermal imaging technology, Herald of Khmelnytskyi National University. Technical Sciences 2016, No. 3, 214-217. 